\title{
Observing and understanding the Earth system variations from space geodesy
}

\author{
Shuanggen Jin ${ }^{\mathrm{a}, *}$, Tonie van Dam ${ }^{\mathrm{b}}$, Shimon Wdowinski ${ }^{\mathrm{c}}$ \\ a Shanghai Astronomical Observatory, Chinese Academy of Sciences, Shanghai 200030, China \\ ${ }^{\mathrm{b}}$ University of Luxembourg, Luxembourg L-1359, Luxembourg \\ c University of Miami, Miami, FL 33149, USA
}

\section{A R T I C L E I N F O}

\section{Article history:}

Received 4 July 2013

Received in revised form 5 August 2013

Accepted 6 August 2013

Available online $\mathrm{xxx}$

\section{Keywords:}

Space geodesy

Earth system

Interaction

Climate change

\begin{abstract}
A B S T R A C T
The interaction and coupling of the Earth system components that include the atmosphere, hydrosphere, cryosphere, lithosphere, and other fluids in Earth's interior, influence the Earth's shape, gravity field and its rotation (the three pillars of geodesy). The effects of global climate change, such as sea level rise, glacier melting, and geoharzards, also affect these observables. However, observations and models of Earth's system change have large uncertainties due to the lack of direct high temporal-spatial measurements. Nowadays, space geodetic techniques, particularly GNSS, VLBI, SLR, DORIS, InSAR, satellite gravimetry and altimetry provide a unique opportunity to monitor and, therefore, understand the processes and feedback mechanisms of the Earth system with high resolution and precision. In this paper, the status of current space geodetic techniques, some recent observations, and interpretations of those observations in terms of the Earth system are presented. These results include the role of space geodetic techniques, atmospheric-ionospheric sounding, ocean monitoring, hydrologic sensing, cryosphere mapping, crustal deformation and loading displacements, gravity field, geocenter motion, Earth's oblateness variations, Earth rotation and atmospheric-solid earth coupling, etc. The remaining questions and challenges regarding observing and understanding the Earth system are discussed.
\end{abstract}

(c) 2013 Elsevier Ltd. All rights reserved.

\section{Introduction}

The Earth system varies continuously due to interactions and coupling between its main fluid components that include the atmosphere, the hydrosphere, the cryosphere, the lithosphere, and the Earth's interior. Mass redistributions driven by geodynamic processes in the Earth system affect the Earth's shape, gravity field and rotation. However, the system and components are also being affected by global climate change. The Intergovernmental Panel on Climate Change (IPCC) of United Nations reported that the global climate has been warming since the middle of the 20th century due to increases in atmospheric greenhouse gas concentrations (Pachauri and Reisinger, 2007). To confirm and assess the future effects of global warming, still requires additional observations. However, traditional meteorological sensors suffer from a number of limitations. In addition to being highly labor-intensive to deploy

\footnotetext{
* Corresponding author at: Shanghai Astronomical Observatory, Chinese Academy of Sciences, Shanghai 200030, China. Tel.: +86 21 34775292; fax: +862164384618.

E-mail addresses: sgjin@shao.ac.cn, sg.jin@yahoo.com (S. Jin), tonie.vandam@uni.lu (T.van Dam), shimonw@rsmas.miami.edu (S. Wdowinski).
}

they also have a low-spatial resolution, e.g., low temporal resolution radiosonde balloons that are launched twice per day (Jin and Luo, 2009; Jin et al., 2009). Another example is ionospheric monitoring, in which traditional instruments are very expensive and provide only low spatial sampling. Furthermore, ionosondes cannot measure the topside ionosphere and sometimes suffer from absorption during storms, whereas Incoherent Scatter Radar (ISR) has geographical limitations, and even low-Earth-orbiting satellite (altitudes of $400-800 \mathrm{~km}$ ) observations cannot provide information on the whole ionosphere (Jin et al., 2006).

Oceans have been observed by drifting buoys and tide gauges (TG) for almost two centuries (Barnett, 1984). Mean sea level rise was observed using TG through the 20th century. Sea-level rise was thought to be driven by a steric component due to the thermal expansion of the oceans and a non-steric component due to fresh water input from the melting of continental ice sheets and glaciers (Holgate and Woodworth, 2004; Church and White, 2006; Feng et al., 2013), that affect our living environments, marine ecosystems, coasts and marshes. However, TG provides the relative sea level variations with respect to the land. Furthermore, TG data are point measurements and are provided at low spatial resolutions. We cannot quantify the steric contribution to the sea level budget due to the lack of global ocean temperature and salinity 
observations. In addition, detailed ocean circulation and the exchange between land and ocean water on a global scale are difficult to measure using traditional instruments.

The solid-Earth's surface and interior are changing constantly because of mantle convection, tectonics, and surface processes. These activities cause displacements and deformations of the Earth's surface, landslides and subsidence, mud-rock flow, and other phenomena. In the past, plate motion was inferred from marine magnetic anomalies located on both sides of the mid-ocean ridges and from the azimuth of transform-faults (at time scales of millions of years), as well as from historic earthquake source parameters. Another issue is that it is difficult to monitor presentday intraplate crustal deformations in sufficient details (Jin and Zhu, 2002). For example, current deformation in East Asia is distributed over a broad area extending from Tibet in the south to the KurilJapan trench in the east with some micro-plates, such as South China and possibly the Amurian plate, embedded in the deforming zone (Jin et al., 2007). Because of the sparse seismicity in the region and the lack of clear geographical boundaries in the broad plate deformation zones, it has been difficult to describe accurately the tectonic kinematics and plate boundaries acting here. Earthquakes and volcanoes frequently occur worldwide, with notable cases including: the Mw=9.1 Sumatra Earthquake in 2004; the $\mathrm{Mw}=8.1$ Wenchuan Earthquake in 2008; the Mw=8.0 Chile Earthquake in 2010; and the $\mathrm{Mw}=9.0$ Tohoku Earthquake in 2011. These earthquakes took thousands of lives and generated huge tsunamis. Seismometers around the globe can estimate the nature of earthquakes, but the details of rapid rupture are usually obscured by the lack of near-field near-real-time observations. In addition, observing and modeling Earth's interior activities are still challenging due to the complex mass transport and other physical processes acting within the Earth system (Jin et al., 2010a; Jin and Feng, 2013).

Therefore, it is hard to observe and model Earth system and environment changes. Today, Earth observations from space provide a unique opportunity to monitor variations in the various components of the Earth system. Observations include data from the dense distribution of ground global positioning system (GPS) stations; high resolution space-borne GPS radio occultation; long-term Very Long Baseline Interferometry (VLBI); Satellite Laser Ranging (SLR); Doppler Orbitography and Radiopositioning Integrated by Satellite (DORIS); Interferometric Synthetic Aperture Radar (InSAR); Light Detection and Ranging (LiDAR); satellite radar and laser altimetry (Abshire et al., 2005); and satellite gravimetry (particularly CHAMP/GRACE/GOCE) (e.g., Tapley et al., 2004). These observations allow us to measure and monitor small displacements of the Earth's surface and mass transport with high precision and high spatial-temporal resolutions. These data provide a unique opportunity to investigate mass transport associated with geodynamics, natural hazards, and climate change and to better understand the processes themselves and their interactions within the Earth system. In this paper, the different space geodetic techniques and Earth system interactions are introduced. Recent observations and modeling results from space geodesy that allow us to infer changes in the atmosphere, oceans, hydrosphere, cryosphere, lithosphere, and the Earth's deep interior are presented.

\section{Space geodetic techniques and observations}

The word "geodesy" etymologically comes from the Greek "geôdaisia": "dividing the Earth". Today, geodesy is defined as measuring the Earth's size, shape, orientation, gravitational field and their variations with time using geodetic techniques, e.g., Arc measurements (historic), Triangulation, Trilateration, Traversing, Leveling, Zenith or vertical angles measurement and ground gravimetry. However, these traditional geodetic techniques are labor intensive. The advent of space geodesy has represented a revolution for the space age and Earth exploration, e.g., VLBI, SLR, DORIS, GNSS, InSAR/LiDAR, and satellite radar and laser altimetry (see Fig. 1). These space geodetic techniques are capable of measuring and precisely monitoring small changes of the parameters they observe with high spatial-temporal resolution. The different roles and uses of each space geodetic technique are summarized in Table 1. In the following discussion, the main space geodetic techniques are briefly introduced.

\subsection{GNSS}

Global Navigation Satellite System (GNSS) is a recent term used to describe the various satellite navigation systems, such as GPS, GLONASS, Beidou and Galileo. The Global Positioning System (GPS) with its unprecedented precision, has provided great contributions to navigation, positioning, timing and scientific questions related to precise positioning on Earth's surface, since it became fully operational in 1994 (Jin et al., 2011a). Today, a number of Earth system science questions have been successfully investigated, including the establishment of a high precision International Terrestrial Reference Frame (ITRF), Earth rotation, geocenter motion, time-variability of the gravity field, orbit determination as well as remote sensing of the atmosphere, hydrology and oceans. With the development of the next generation of multi-frequency and multi-system GNSS constellations, including the U.S.'s modernized GPS-IIF and planned GPS-III, Russia's restored GLONASS, the coming European Union's GALILEO system, and China's Beidou/COMPASS system, as well as a number of regional systems including Japan's Quasi-Zenith Satellite System (QZSS) and India's Regional Navigation Satellite Systems (IRNSS), more applications and opportunities will be realized to explore the Earth system using ground and space borne GNSS.

\subsection{VLBI}

Very-long-baseline interferometry, VLBI, plays a key role in space geodesy by receiving natural quasars signals at two or more Earth-based radio telescopes. VLBI is particularly important in establishing the International Celestial Reference Frame (ICRF). With the global VLBI tracking network, VLBI can be used to monitor plate motion, crustal deformation, polar motion and length-of-day as well as being used for deep space exploration. The "VLBI2010: Current and Future Requirements for Geodetic VLBI Systems" provided a path to a next-generation system with unprecedented new capabilities and accuracies, including $1 \mathrm{~mm}$ position and $0.1 \mathrm{~mm} /$ year velocity measurement accuracy, continuous observations for station positions and Earth orientation parameters. Additional applications will be developed in the near future (Titov, 2010). For example, the Chinese VLBI Network (CVN) has been upgraded (e.g., two VLBI radio telescopes in Shanghai and Urumqi, and several proposed new VLBI2010-type system) and new applications such as successfully tracking the China's Chang'E1/2 lunar exploration probes (Wei et al., 2013).

\section{3. $S L R / L L R$}

Satellite Laser Ranging (SLR) systems precisely determine the distance of the satellites above the Earth's geocenter by measuring the time to send and receive short laser pulses. These data have been widely used in precise orbit determination (POD) of artificial satellites and station motions. In addition, since the low-earth-orbit (LEO) laser ranging satellites are sensitive to the low-degree gravity field, SLR is considered the gold-standard in monitoring geocenter and $C_{20}$ (Cheng and Tapley, 2004; Jin et al., 2011b). Lunar Laser Ranging (LLR) can measure the distance between the moon and 


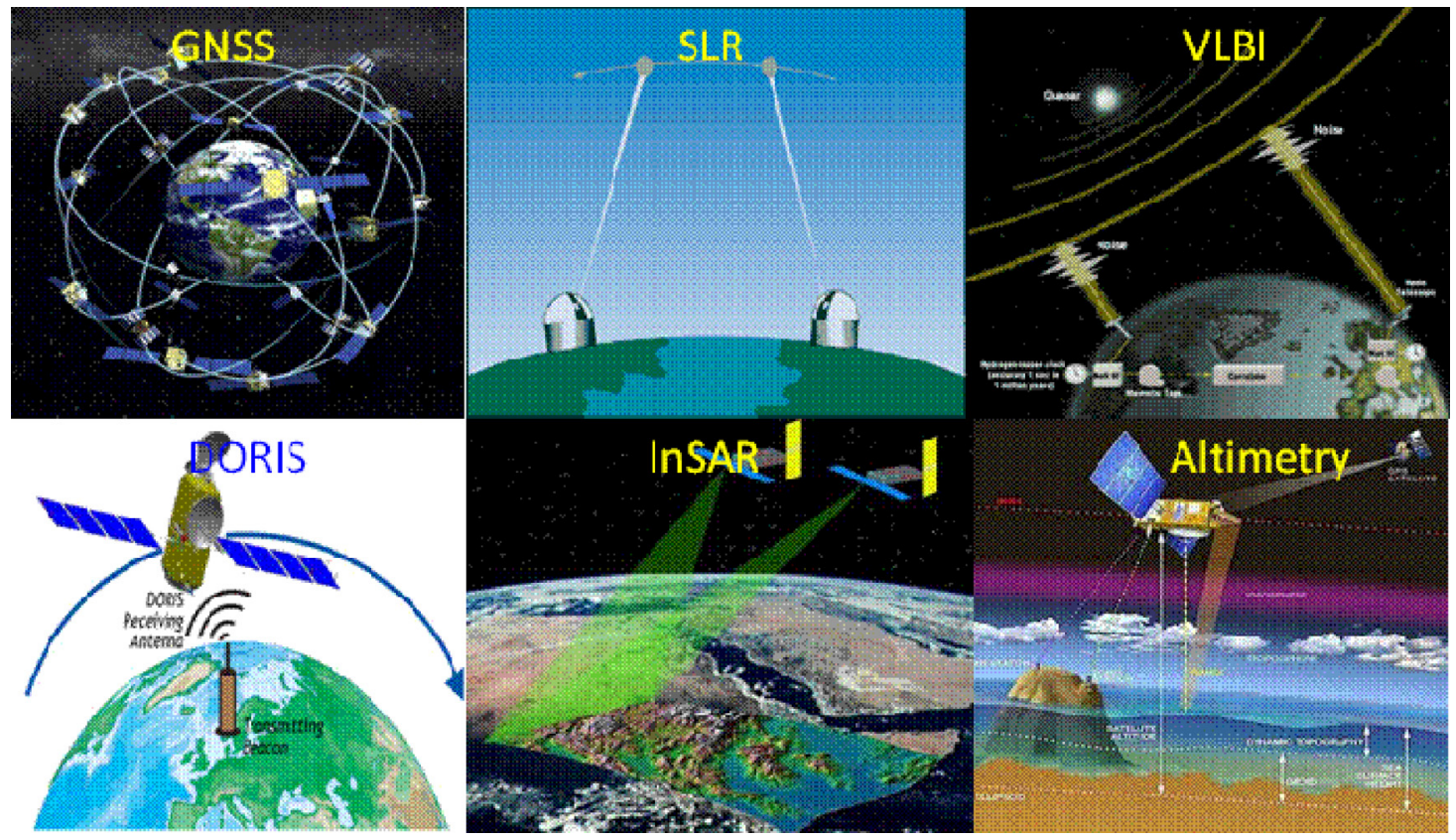

Fig. 1. Main space geodetic techniques.

Earth, which allows us to check certain general relativity principals and explore rotational properties of the moon.

\subsection{DORIS}

Doppler Orbitography and Radio positioning Integrated by Satellite (DORIS) is a technique whereby satellites receive the broadcasted wavelength signal transmitted by ground stations. As the satellite moves, the received frequency is shifted. The satellite velocity and position are linked by the Keplerian equation of its orbit, so the Doppler shift allowing us to determine the station to satellite distance. DORIS can determine the orbit of the transmitting satellites, Earth rotation and station coordinates that can be used in different geodetic applications (see Willis et al., 2010).

\subsection{InSAR}

Interferometric Synthetic Aperture Radar (InSAR) can be used monitor surface deformation or determine digital elevation model (DEM) using differences between two or more synthetic aperture radar (SAR) images (Massonnet and Feigl, 1998). The technique can potentially measure displacement of the Earth's surface over time spans of days to years with centimeter level precision. Recently, many varied applications of InSAR have been published, e.g., monitoring earthquakes, volcanoes, landslides, hydrological cycle, ocean environment, and glacier movement. In addition, tropospheric and ionospheric delays can be extracted using the InSAR technique. These data can be used in meteorology and space weather.

\subsection{Satellite altimetry}

Satellite altimetric observations have promoted and advanced oceanographic research since the first mission Topex/Poseidon in 1993 as well as later GEOSAT Follow-On (GFO), ERS-2, Jason-1/2, and Envisat. A number of results have been obtained with almost covering the whole Earth at centimeter accuracy, e.g., the mean sea surface height (MSSH), sea level change and ocean circulation as well as El Nino events monitoring (Feng et al., 2013). In addition, laser altimeter also can monitor glacier melting. For example, the Geoscience Laser Altimeter System (GLAS) on bard ICESat can monitor the ice sheet mass balances (Zwally et al., 2005; Abshire et al., 2005).

Table 1

Roles and uses of each space geodetic technique.

\begin{tabular}{|c|c|c|c|c|c|c|c|c|}
\hline Parameters & GNSS & VLBI & DORIS & SLR & LLR & Altimetry & InSAR/LiDAR & Gravimetry \\
\hline ICRF & & $\sqrt{ }$ & & & & & & \\
\hline ITRF & $\sqrt{ }$ & $\sqrt{ }$ & $\sqrt{ }$ & $\sqrt{ }$ & $\sqrt{ }$ & $(\sqrt{ })$ & $(\sqrt{ })$ & $(\sqrt{ })$ \\
\hline Polar motion & $\sqrt{ }$ & $\sqrt{ }$ & $\sqrt{ }$ & $\sqrt{ }$ & $\sqrt{ }$ & & & $(\sqrt{ })$ \\
\hline Nutation & $(\sqrt{ })$ & $\sqrt{ }$ & & $(\sqrt{ })$ & $\sqrt{ }$ & & & \\
\hline UT1 & & $\sqrt{ }$ & & & & & & \\
\hline Length of day & $\sqrt{ }$ & $\sqrt{ }$ & $\sqrt{ }$ & $\sqrt{ }$ & $\sqrt{ }$ & & & $(\sqrt{ })$ \\
\hline Geocenter & $\sqrt{ }$ & & $\sqrt{ }$ & $\sqrt{ }$ & & $(\sqrt{ })$ & & $\sqrt{ }$ \\
\hline Gravity field & $\sqrt{ }$ & $\sqrt{ }$ & $\sqrt{ }$ & $\sqrt{ }$ & $(\sqrt{ })$ & $\sqrt{ }$ & & $\sqrt{ }$ \\
\hline Plate motion & $\sqrt{ }$ & $\sqrt{ }$ & $\sqrt{ }$ & $\sqrt{ }$ & $(\sqrt{ })$ & $(\sqrt{ })$ & $\sqrt{ }$ & $\sqrt{ }$ \\
\hline LEO orbits & $\sqrt{ }$ & $\sqrt{ }$ & $\sqrt{ }$ & $\sqrt{ }$ & $\sqrt{ }$ & $\sqrt{ }$ & & \\
\hline Navigation/orbit & $\sqrt{ }$ & $\sqrt{ }$ & $\sqrt{ }$ & $\sqrt{ }$ & $\sqrt{ }$ & $\sqrt{ }$ & & \\
\hline Timing and clock & $\sqrt{ }$ & $\sqrt{ }$ & & $(\sqrt{ })$ & & & & \\
\hline Ionosphere & $\sqrt{ }$ & $\sqrt{ }$ & $\sqrt{ }$ & & & $\sqrt{ }$ & $\sqrt{ }$ & \\
\hline Troposphere & $\sqrt{ }$ & $\sqrt{ }$ & $\sqrt{ }$ & & & $\sqrt{ }$ & $\sqrt{ }$ & \\
\hline Hydrology & $\sqrt{ }$ & & & & & $\sqrt{ }$ & $\sqrt{ }$ & $\sqrt{ }$ \\
\hline Oceans & $\sqrt{ }$ & & & & & $\sqrt{ }$ & $\sqrt{ }$ & $\sqrt{ }$ \\
\hline
\end{tabular}

Please cite this article in press as: Jin, S., et al., Observing and understanding the Earth system variations from space geodesy. J. Geodyn. (2013), http://dx.doi.org/10.1016/j.jog.2013.08.001 


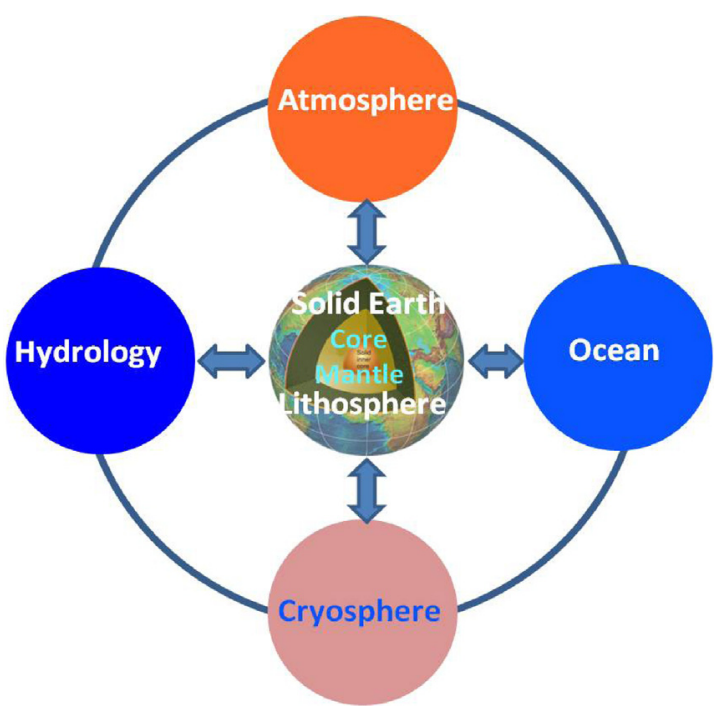

Fig. 2. Earth system components and interaction.

\subsection{Satellite gravimetry}

With the recent development of the low-earth orbit (LEO) satellite gravimetry, the precision and temporal resolution of the Earth's gravity field model has been greatly improved. Satellite gravimetry is a successful innovation and breakthrough in the field of geodesy, following the Global Positioning System (GPS). Unlike the traditional terrestrial gravity measurements, the most advanced SST (Satellite-to-Satellite Tracking) and SGG (Satellite Gravity Gradiometry) techniques are used to estimate the global high-precision gravity field and its variations (Knudsen et al., 2011). Satellite-to-Satellite Tracking technique includes the socalled high-low satellite-to-satellite tracking (hl-SST) and low-low satellite-to-satellite tracking (ll-SST) (Wolff, 1969), which can precisely determine the variation rate of the distance between two satellites. Satellite gravimetry, particularly recent Gravity Recovery and Climate Experiment (GRACE), can monitor the mass transport and redistribution in the Earth system, which has been widely applied in geodesy, oceanography, hydrology, ice mass change, geodynamics and geophysics (Wahr et al., 1998; Tapley et al., 2004; Famiglietti et al., 2011; Jin and Feng, 2013).

\section{Space geodesy and earth system interaction}

The Earth system is very complex due to the interaction and coupling of its components (Fig. 2). For example, melting continental glaciers will result in rising sea levels, tectonic activities and reservoir accumulated water may lead to hazards, e.g., earthquakes, tsunamis, landslides and mud-rock flows and the atmospheric pressure loading will change the shape, geocenter, oblateness and rotation of the Earth, etc.

Today space geodetic techniques with high precision and temporal-spatial resolution can measure and monitor such changes within the Earth system, including Earth rotation, Earth's oblateness, geocenter, geometry and deformation, gravity field, atmosphere, oceans, hydrosphere, cryosphere, crust, ocean/atmospheric/polar tides, ocean/atmospheric/hydrological loading, tectonic motions, volcanoes, earthquakes, tsunamis, glacier istostatic adjustment (GIA) and landslides, etc. Fig. 3 shows the role of space geodesy in observing and understanding the Earth system. The reference frame is a benchmark for Earth rotation, geometry and deformation and gravity field measurements that can be precisely determined using space geodesy. Earth system changes

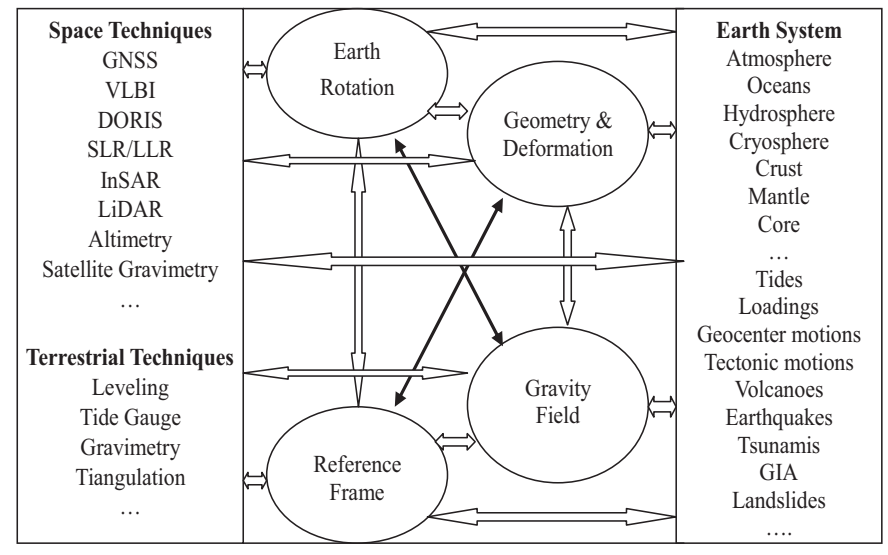

Fig. 3. Space geodesy and earth system interaction.

affect the Earth's rotation, geometry and deformation and gravity field as well as reference frame.

\section{Observing and understanding Earth system}

\subsection{Atmospheric sounding}

Space techniques' radio signals propagate through the Earth's neutral atmosphere and ionosphere. This results in lengthening the geometric path of the ray, usually referred to as the "tropospheric delay and ionospheric delay." These delays are one of major error sources for space techniques. Today, the space techniques such as GPS, VLBI, InSAR, DORIS and altimetry are able to measure such delays and corresponding precipitable water vapor (PWV) and ionospheric total electron content (TEC) with a high resolution and precision. These products have been widely applied in meteorology, climatology, numerical weather models, atmospheric science and space weather (e.g., Jin et al., 2006; Jin and Park, 2007; Jin et al., 2008, 2009; Jin and Luo, 2009). For example, Fig. 4 shows the long-term vertical TEC variations from GPS at the
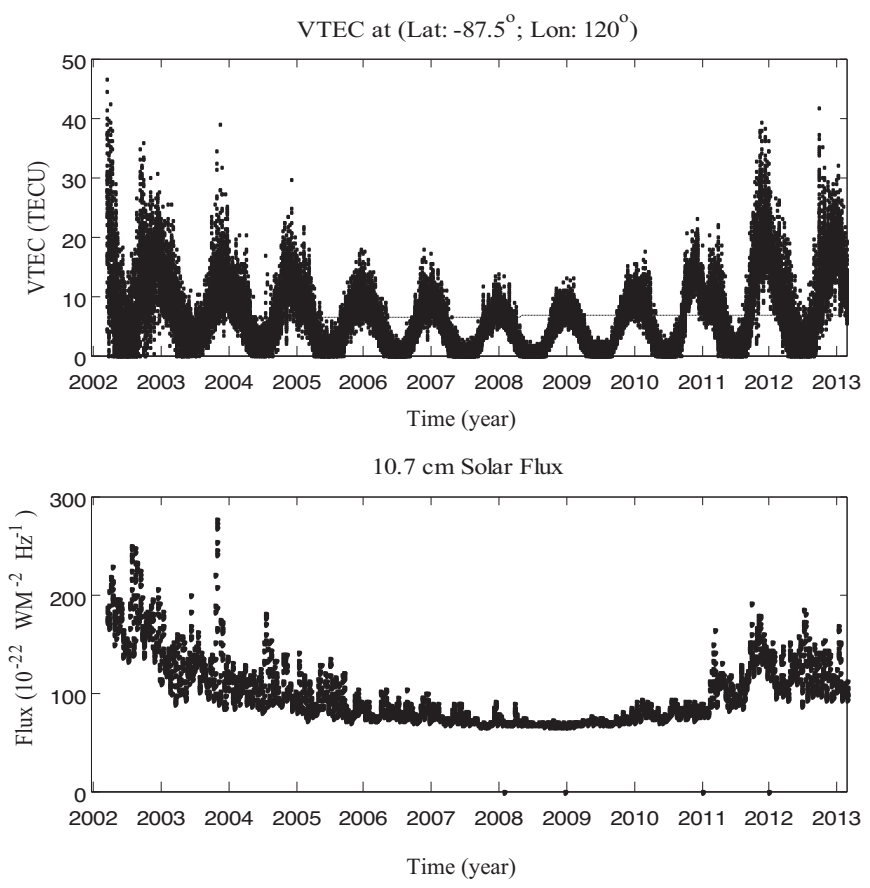

Fig. 4. Vertical TEC (VTEC) time series at $\left(120 \mathrm{E}^{\circ},-87.5 \mathrm{~S}^{\circ}\right)$ and $10.7 \mathrm{~cm}$ Solar Flux. 
point $\left(120 \mathrm{E}^{\circ},-87.5 \mathrm{~S}^{\circ}\right)$, which are mainly affected by solar activity. Additionally, the space-borne GPS radio occultation (RO) missions can estimate atmospheric and ionospheric products, including the pressure, temperature, water vapor, total electron content (TEC) and electron density as well as their variation characteristics, e.g., the US/Argentina SAC-C, German CHAMP (CHAllenging Minisatellite Payload), US/Germany GRACE (Gravity Recovery and Climate Experiment), Taiwan/US FORMOSAT-3/COSMIC (FORMOsa SATellite mission - 3/Constellation Observing System for Meteorology, Ionosphere and Climate) satellites, the German TerraSAR-X satellites and the European MetOp (Schmidt et al., 2010; Jin et al., 2011a).

\subsection{Ocean monitoring}

The oceans have been well monitored by satellite altimetry for about two decades. These data provide information on the mean sea surface height (MSSH), ocean circulation, tides and sea level change. The sea level change includes the steric and non-steric sea changes. While the steric sea level change, i.e., thermal expansion, is well estimated by Argo observations, the non-steric component, i.e., eustatic sea level change, related to mass changes driven by the addition of water to the oceans from the melting of continental ice sheets and fresh water in rivers and lakes (Feng et al., 2013) is more difficult to estimate. The difficulty is due to the highly uncertain estimates of the Antarctic and Greenland mass and land reservoirs. The satellite-based GRACE observations provide a unique opportunity to directly measure the global ocean and continental water mass change. For example, Fig. 5 shows the sea level change in $\mathrm{cm} /$ year from satellite altimetry, Argo and GRACE (2002-2011), which generally quantify the total sea level change budget.

In addition, GNSS-Reflectometry (GNSS-R) is a new innovative and promising approach in ocean remote sensing. In addition, the technique poses many potential advantages (Jin et al., 2011a), including primarily global coverage and long-term satellite mission lifetime. In the last few years, several experiments were undertaken and numerous advancements were realized. The first GPS signals reflected from the sea surface inside tropical cyclones were analyzed, and the wind speed results were obtained (Katzberg et al., 2001). Currently, the GPS reflected signals from the ocean surface can measure sea surface height with the achievable accuracy (Martin-Neira et al., 2001; Katzberg and Dunion, 2009).

\subsection{Hydrologic sensing}

The power level of the GPS reflected signal from the land contains information about the soil moisture, dielectric constant, surface roughness, and possible vegetative cover of the reflecting surface. Katzberg et al. (2006) obtained the soil reflectivity and dielectric constant using a GPS reflectometer installed on an HC130 aircraft during the Soil Moisture Experiment 2002 (SMEX02) near Ames, Iowa, which were consistent with results found for other microwave techniques operating at L-band. In addition, the multi-path from ground GPS networks is possibly related to the near-surface soil moisture. Larson et al. (2008) found nearly consistent fluctuations in near-surface soil moisture from the ground-based observations of GPS multi-path. They found GPS estimates of soil moisture were comparable to estimates in the top $5 \mathrm{~cm}$ of soil measured from conventional sensors.

Satellite gravimetry, in particular GRACE, can determine the monthly terrestrial water storage change. Fig. 6 shows the trend of terrestrial water storage change in the world based on GRACE data (August 2002-February 2011), which reflect groundwater depletion, drought and floods. For example, the terrestrial water storage is falling by about $-15.5 \mathrm{~mm} / \mathrm{year}$ in the northwest region of India due to groundwater depletion (Rodell et al., 2009). The Amazon basin in South American has increased rates of terrestrial water (a) Sea level change from Satellite Altimetry

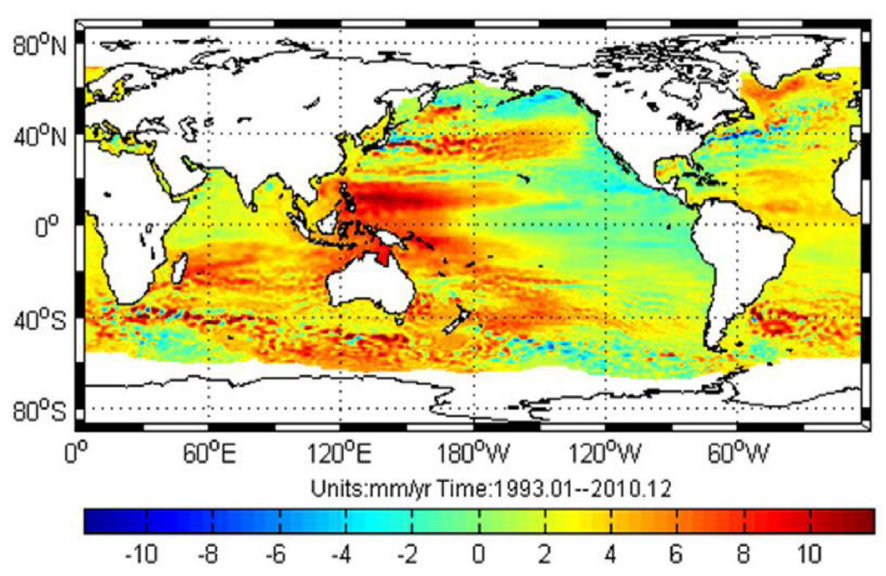

(b) Steric sea level change from Argo

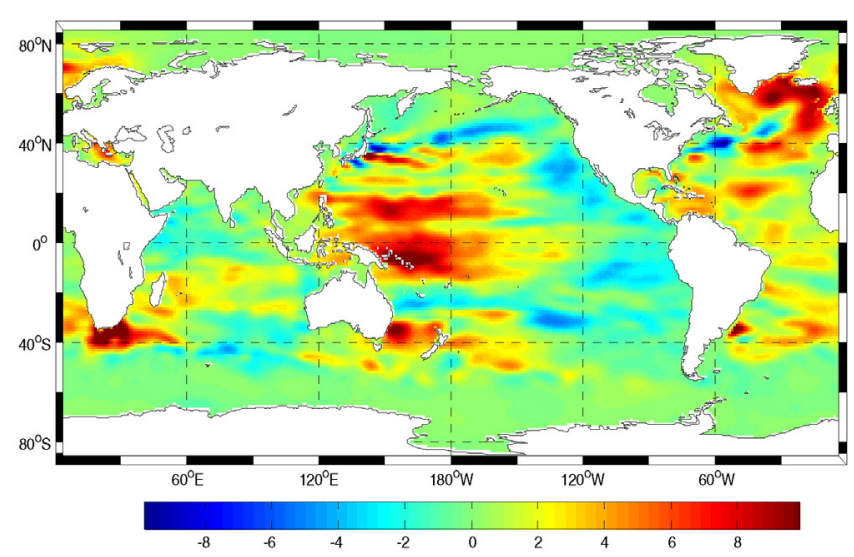

(c) Non-steric sea level change from GRACE

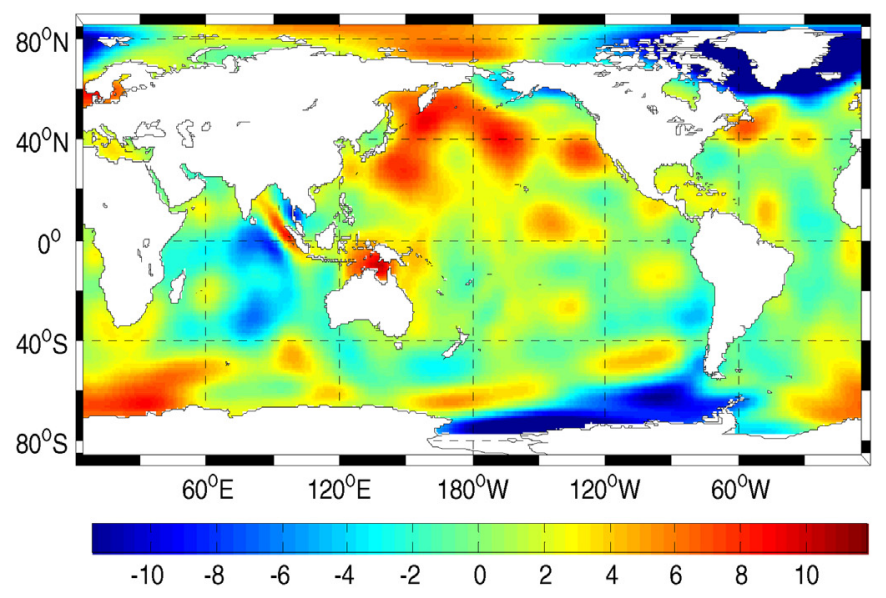

Fig. 5. Sea level change in $\mathrm{cm} / \mathrm{year}$ from satellite altimetry, Argo and GRACE (2002-2011).

storage reserves with about $20.5 \mathrm{~mm} /$ year due to recent floods. In the La Plata region of South America, the terrestrial water storage is falling at a rate of $-9.8 \mathrm{~mm} /$ year due to recent droughts.

\subsection{Wetland mentoring by InSAR}

Wetland InSAR is a unique application of the InSAR technique, because unlike all other applications that detect displacements of solid surfaces, wetland InSAR detects changes of aquatic surfaces. The method works, because the radar pulse is backscattered twice 


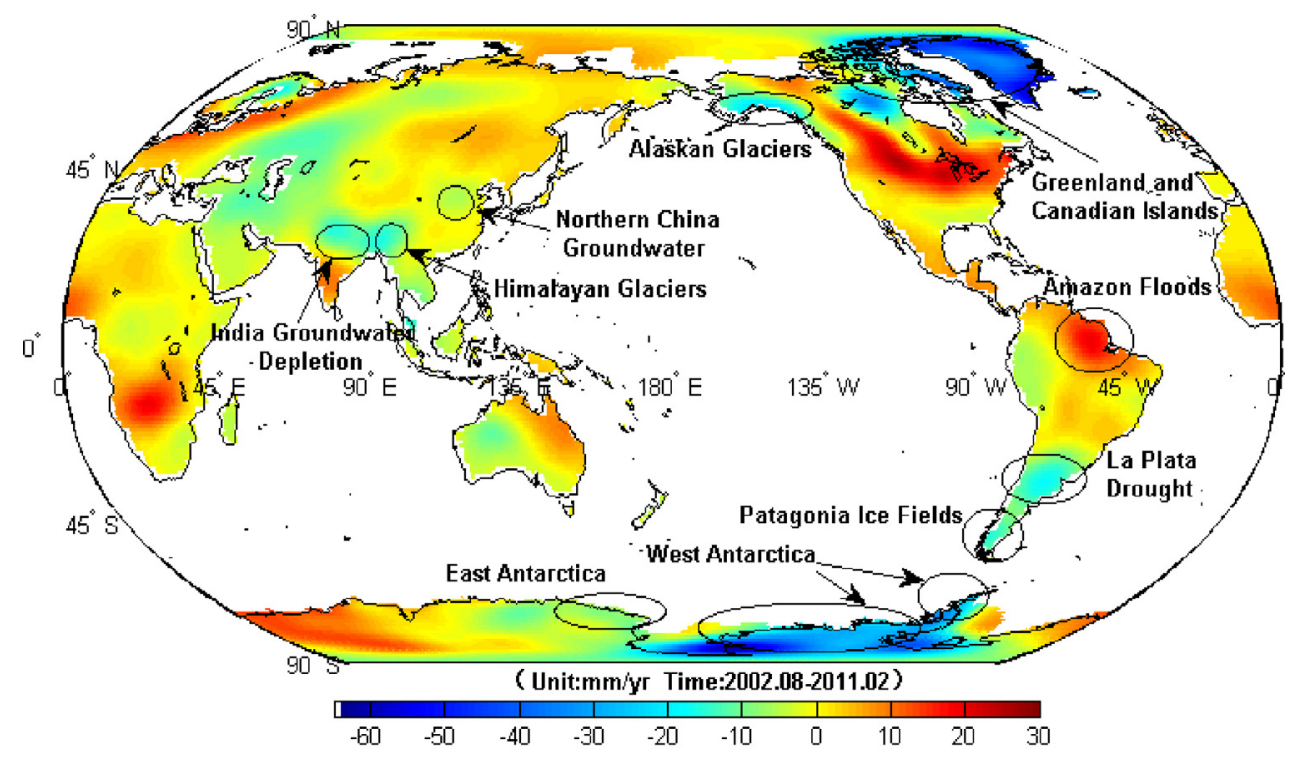

Fig. 6. The trend of terrestrial water storage from GRACE (2002-2011).

(“double-bounce" - Richards et al., 1987) from the water surface and vegetation. Although most vegetation scattering theories suggest that the short wavelength radar signal (X- and C-band), as well as the cross-polarization signal, interacts mainly with upper levels of the vegetation and, hence, should be suitable for repeat pass interferometry, the analysis of all data types with different polarizations have indicated the suitability of all inSAR data to the wetland application (Hong et al., 2010a; Hong and Wdowinski, 2011). However the data quality, as calculated from interferometric coherence, strongly depends on the time span between the InSAR acquisitions. Short wavelength signals (X- and C-band) maintain coherence when the acquisition time span is in the range of 1-70 days, depending on the acquisition parameters and the vegetation type, whereas the longer wavelength L-band can maintain coherence up to three years in a woody wetland environment (Kim et al., 2013).

Wetland InSAR works very well in wetlands and floodplains enabling high spatial resolution detection of water level changes with 5-10 cm level accuracy (Wdowinski et al., 2004, 2008). By combining the InSAR observations with ground-measured stage (water level) data, it is possible to generate high spatial resolution maps of absolute water levels and their changes over time (Hong et al., 2010b). Wetland InSAR observations are useful for wetland monitoring by water authorities, characterization of tidal flushing zone (Wdowinski et al., 2013), and constraints of high spatial resolution surface flow model.

\subsection{Cryosphere mapping}

Glaciers can also be monitored by radar remote-sensing (e.g., InSAR). However, coverage is limited and costs are high. As the ice and snow thickness are related to the amplitude of the reflected signal as a function of the incidence angle or relative amplitudes between different polarizations, the snow and ice thickness can be retrieved from the GPS reflected signals. Komjathy et al. (2000) derived the condition of sea and fresh-water ice as well as the freeze/thaw state of frozen ground from aircraft experiments with GPS reflections over the Arctic sea ice and ice pack near Barrow, Alaska, USA. In addition, the change in snow depth is also related to the corresponding multi-path modulation of the ground-based GPS signal, which can be monitored by GPS (Jacobson, 2010). In addition, GRACE can determine well the glacier and ice-sheet mass variations. For example, Fig. 6 shows rapid melting of glaciers in Greenland, West Antarctica and Alaska.

\subsection{Crustal deformation monitoring}

Space geodetic techniques, particularly the denser GPS observations, provide new tools to monitor and model the present-day crustal deformation associated with hazards. For example, East Asia is located in a complex convergent zone with several plates, e.g., Pacific, North American, Eurasian, and Philippine Sea plates (Jin and Zhu, 2003). Subduction of the Philippine Sea and Pacific plates and expulsion of Eurasian plate with Indian plate collision making this region one of the most seismically active and deforming regions in the world. Current deformation in East Asia is distributed over a broad area extending from Tibet in the south to the Baikal Rift zone in the north and the Kuril-Japan trench in the east. The interplate deformation and interaction between the blocks are very complicated and active. Because of low seismicity and uncertainties in the geographical boundary of faults, it is difficult to accurately determine the crustal deformation and describe the tectonic features and evolution of the deformation belts in East Asia. With more GPS observations in East Asia, the system will provide new ways to clearly monitor the detailed crustal deformation, e.g., the national projects "Crustal Movement Observation Network of China (CMONC) with more than 1000 GPS sites and the Japanese GPS Earth Observation Network (GEONET) with more than 1000 continuous GPS sites. These dense GPS observations will obtain a more accurate estimate of crustal deformation in East Asia. Fig. 7 shows crustal deformation rates in the Eurasia plate (EU) fixed reference frame with error ellipses in $95 \%$ confidence limits. The possibility of micro-plate motion independent of the Eurasian plate was tested and the characteristics of tectonic activities were given using GPS derived velocities (Jin et al., 2007).

\subsection{Geophysical loading}

Continuous GPS observations have significant seasonal changes, which are mostly excited by the redistribution of the surface fluid mass (including atmosphere, ocean, and continental water) (van Dam and Wahr, 1987; van Dam et al., 2001; Dong et al., 2002). However, various empirical models have larger differences, particularly hydrological models due mainly to the lack of a comprehensive 


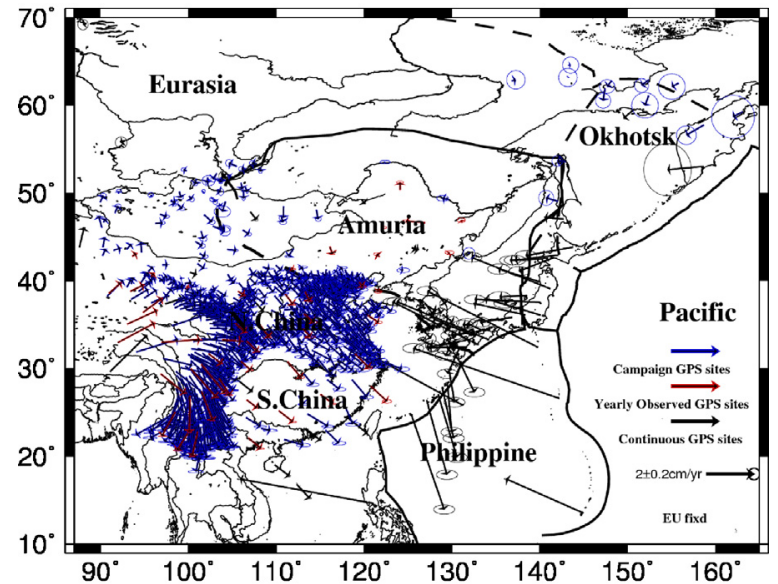

Fig. 7. Crustal deformation rates in the Eurasia plate(EU) fixed reference frame with error ellipses in $95 \%$ confidence limits.

global network for routine monitoring of the appropriate hydrological parameters. The satellite mission, GRACE, has provided global surface fluid mass transport for more than a decade. The vertical loading displacements from GPS, GRACE and geophysical models are computed and compared, and at most global sites, the root mean square (RMS) of GPS coordinate time series is reduced after removing the GRACE and models estimates, and the annual variations of the GPS height at most sites agree well with GRACE estimates in the amplitude and phase (Fig. 8) (Zhang et al., 2012). For example, Fig. 9 shows the vertical displacement time series from GPS, GRACE and geophysical models at BRAZ site. It indicates that the nonlinear seasonal GPS vertical displacement variations are mainly caused by the geophysical loading effects. However, at some sites, particularly in the Antarctica, some ocean coasts, small peninsulas and Europe, discrepancy has been found between the GPS and GRACE estimates (e.g., van Dam et al., 2007). The remaining disagreement may be due to the GPS technical errors and GRACE accuracy (e.g.,

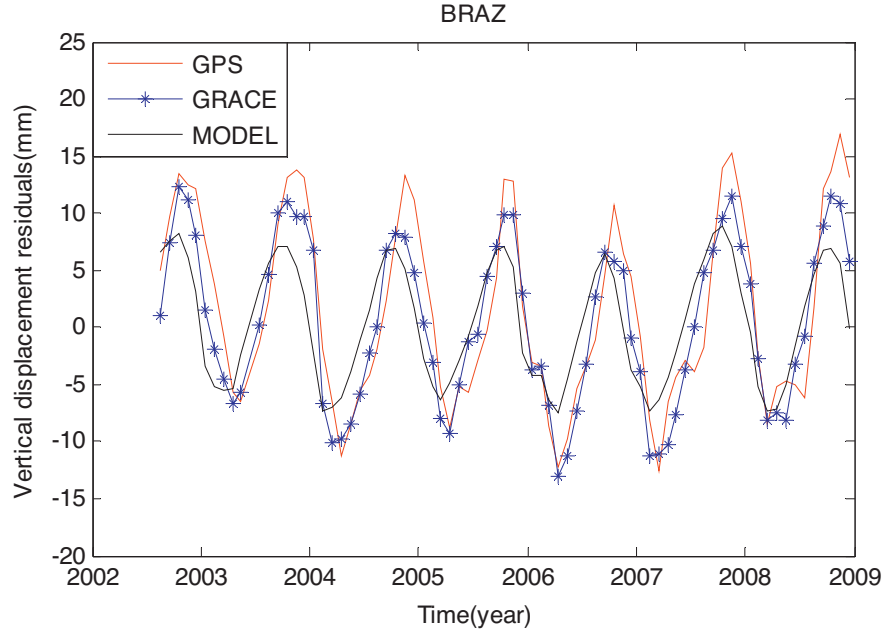

Fig. 9. Monthly vertical displacement time series from GPS, GRACE and geophysical models at BRAZ site.

Jin et al., 2005). It needs to be further investigated using longer and more GPS and GRACE measurements.

\subsection{Geocenter and Earth's oblateness variations}

The transfer and redistribution of the Earth's atmosphere, ocean and land water masses due to the tectonic activities and global climate change can lead to variations of Earth's oblateness $\left(J_{2}\right)$ and geocenter motion (Jin et al., 2010a, 2011b). Satellite laser ranging (SLR) can well estimate the geocenter motion and degree-2 zonal gravitational coefficient variations, but subjecting to sparse and unevenly distributed SLR stations as well as higheraltitude laser satellites. Although the new generation of satellite gravity GRACE has largely improved the lower-order coefficient estimates with orders of magnitude, but is not sensitive to geocenter and $J_{2}$. Nowadays, continuous GPS observations can provide high precision 3-dimensional coordinate time series, which can

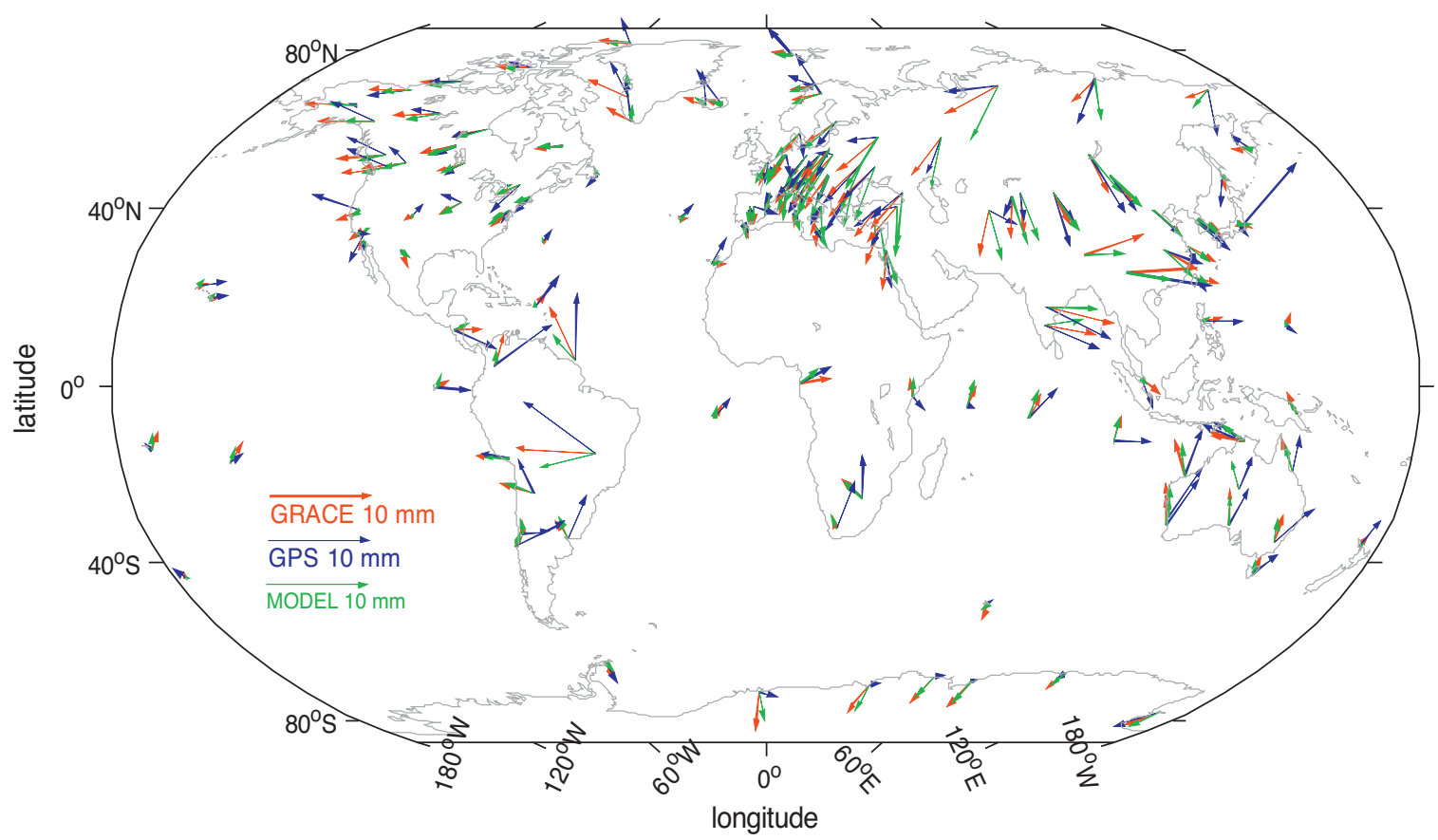

Fig. 8. Annual variations of vertical displacements from GPS, GRACE and geophysical models. 


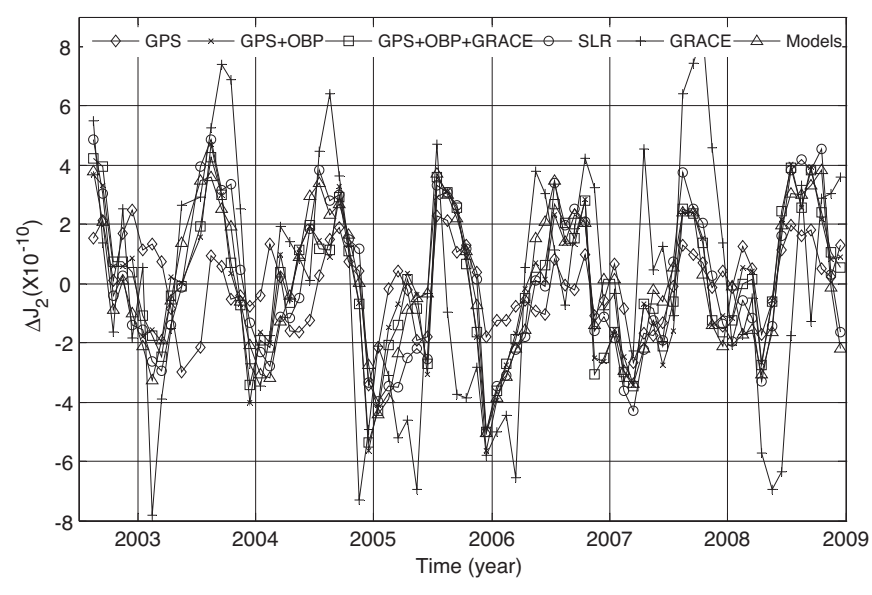

Fig. 10. The time series of Earth's oblateness variations.

estimate low degree gravity field coefficients (Wu et al., 2006; Jin and Zhang, 2012). Here, the GPS coordinates time series from ITRF2008 solutions (Altamimi et al., 2011) are used to estimate geocenter and $J_{2}$ together with OBP (ocean bottom pressure) and GRACE, respectively, which show good agreement with SLR solutions and geophysical models estimates in seasonal, intraseasonal and interannual variations. For example, Fig. 10 shows the time series of Earth's oblateness variations from GPS, GPS + OBP, GPS + OBP + GRACE, SLR, GRACE and Models (Jin and Zhang, 2012). The variations of $J_{2}$ at seasonal, intraseasonal and interannual scales are mainly driven by the atmosphere, oceans and hydrology.

\subsection{Geophysical excitations of Earth rotation}

The Earth's rotation variables are changing from seconds to decades of years, including polar motion ( $X$ and $Y$ ) and change of rotation rate (or length-of-day, LOD). At timescales of a few years or less, the Earth's rotational changes are mainly driven by mass redistribution in the atmosphere, oceans and hydrosphere from geophysical fluid models (e.g., Barnes et al., 1983; Gross et al., 2003). However, accurately assessing the atmospheric, hydrological and oceanic effects on polar motion and length-of-day variations remains unclear due mainly to the lack of global observations (Jin et al., 2012). Here the atmospheric, hydrological and oceanic mass excitations to polar motion are investigated from geophysical fluid models (NCEP + ECCO + GLDAS) and Gravity Recovery and Climate Experiment (GRACE) for August 2002 until August 2009. Results show that the GRACE explains the geodetic residual polar motion excitations at annual periods better (see Fig. 11). However, the geophysical fluid models do a better job of capturing the intraseasonal geodetic residuals of polar motion excitation in the Px and Py components. In addition, GRACE and the combined GRACE and SLR solutions better explain the geodetic LOD excitations at annual and semi-annual time scales. For less than 1-year time scales, GRACEderived mass does worse at explaining the geodetic residuals, while SLR agrees better with the geodetic residuals. However, the combined GRACE and SLR results are much improved in explaining the geodetic residual excitations at intraseasonal scale (Jin et al., 2011b).

\subsection{Atmospheric-solid Earth coupling}

GNSS/InSAR and strong motion seismic measurements provide unique insights into the kinematic rupture and the size of the earthquake (Jin et al., 2010b). However, based on current measurements understanding and predicting earthquakes is still challenging and difficult. Possibly non-seismic measurements, e.g., atmospheric,
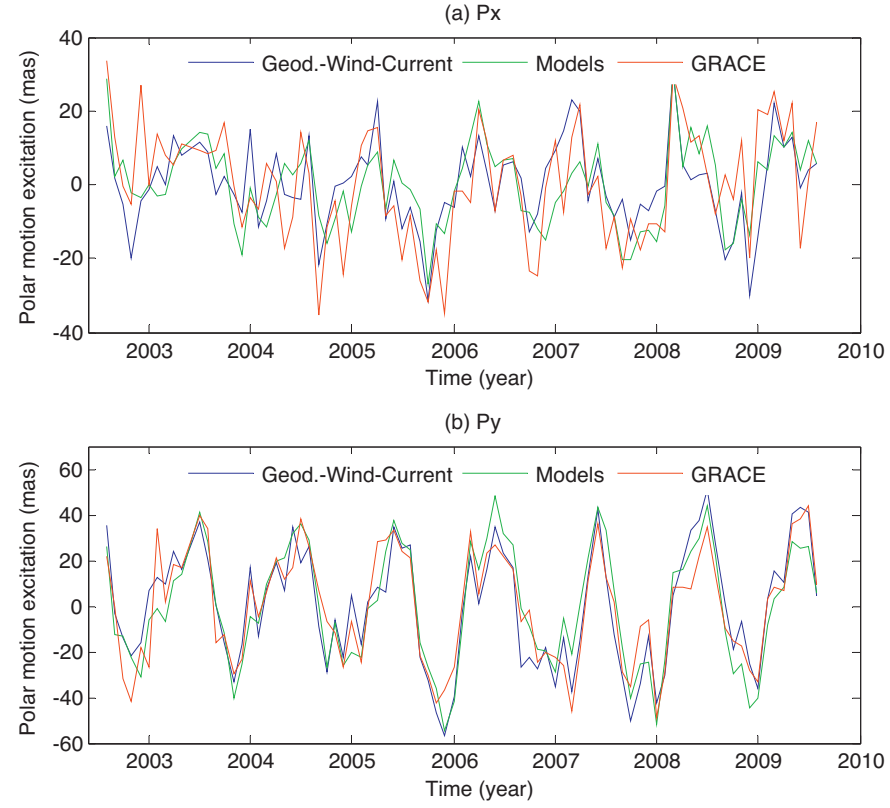

Fig. 11. Surface fluid mass excitations of polar motion from geodetic observation residual (Geod.-Wind-Current) (blue line), geophysical models (NCEP + ECCO + GLDAS) (green line) and GRACE (red line). (For interpretation of the references to color in this figure legend, the reader is referred to the web version of the article.)

ionospheric or electromagnetic observations, can help in this task. A case study of the 2008 Wenchuan earthquake was performed using continuous GPS measurements in China. Significant ionospheric disturbances are found at continuous GPS sites near the epicenter with an intensive $\mathrm{N}$-shape shock-acoustic wave propagating southeastward, almost consisting with seismometer, indicating that the co-seismic ionospheric TEC disturbances were mainly derived from the main shock. For example, Fig. 12 shows the significant TEC variations during the mainshock, indicating a significant ionospheric disturbance (Afraimovich et al., 2010; Jin et al., 2010b) that occurs simultaneously with the co-seismic rupture. Furthermore, the coseismic tropospheric anomalies during the mainshock are also found, mainly in the zenith hydrostatic delay component (ZHD) (Jin et al., 2011c). This conclusion is supported by the same pattern of surface observed atmospheric pressure changes at co-located GNSS site that are driven by the ground-coupled air waves from ground vertical motion of seismic waves propagation. Therefore, the coseismic atmospheric disturbances appear to indicate an acoustic coupling between the atmosphere and solid-Earth with air wave propagation from the ground to the top atmosphere.

\section{Challenges and future developments}

Although high precision space geodesy plays a key role in observing and understanding the Earth system, a number of questions still remain, e.g., the precision and temporal-spatial resolution of the techniques. For example, currently VLBI cannot continuously observe and SLR has a few global tracking stations, particularly in the southern hemisphere. Furthermore, laser ranging satellites are not sensitive to the high-frequency variations of low-degree gravity field because of the high altitude of their orbits, e.g., LEGEOS $1 / 2$ with altitude of $6000 \mathrm{~km}$ (Cheng and Tapley, 2004). Satellite gravimetry, in particular GRACE, is also restricted in precision and resolution due to its orbital altitude, orbital inclination, hardware noise and filtering methods (Swenson and Wahr, 2006). In addition, the accuracy of geophysical models, post-glacial rebound (Zhang and Jin, 2013) and tide models also affect mass 

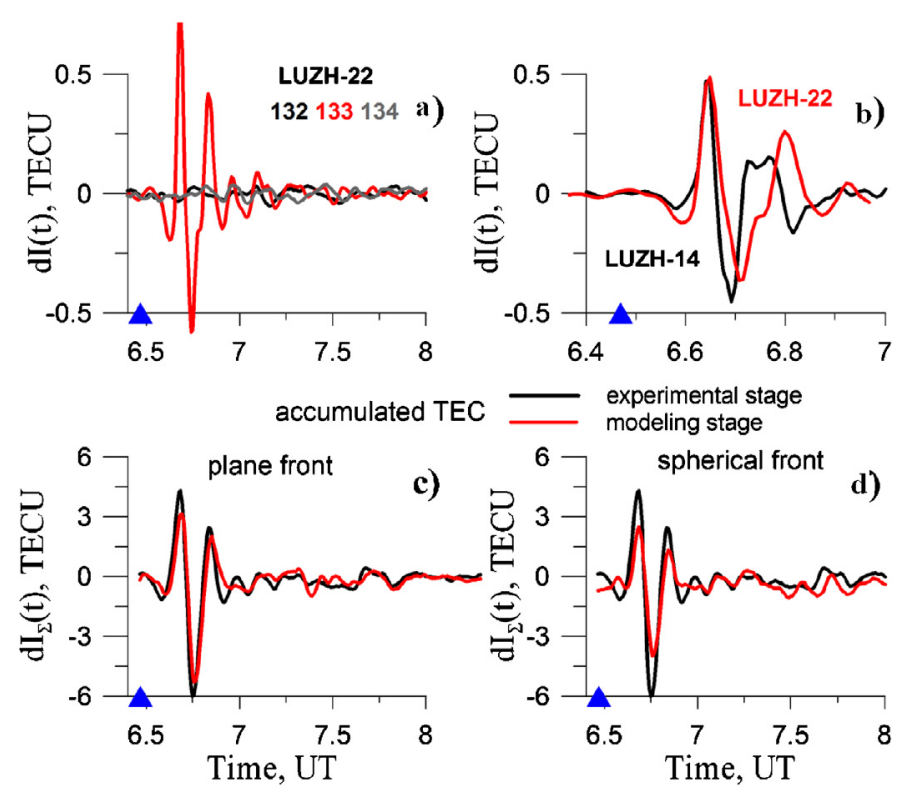

Fig. 12. The filtered TEC series $d I(t)$ for LUZH-PRN22 (a) with black, red, and gray lines on 11,12 and 13 May, respectively. (b) Demonstrates the evolution of N-shaped response with distance from epicenter increase; the first maximums of $\mathrm{N}$-response for LUZH-PRN14 and LUZH-PRN22 are superposed. On panels (c) and (d) the black lines show the accumulated TEC series $\mathrm{d} I P(t)$, obtained on the experimental stage of processing for the plane and spherical wave front, respectively (QOA method). The red and gray lines on panels (c) and (d) mark the modeled $d I P(t)$ for which the maximum of function $C$ was reached. The moment of the main shock of the Wenchuan earthquake is marked by blue shaded triangles. (For interpretation of the references to color in this figure legend, the reader is referred to the web version of the article.)

transport results. With the launch of the next generation of gravity satellites, improvement of measurement precision, data processing methods, geophysical models, and extension of the observation time, we will be able to detect with higher precision global terrestrial water storage and ocean mass variations to get more detailed information of Earth system.

GNSS has greatly advanced geoscience and Earth system science since 1994, but lots of error sources are still not resolved (e.g., Jin et al., 2005; Chen et al., 2013). In addition, activities in the Earth's interior, such as processes and stress transfer during pre-, co- and post-earthquake, cannot be monitored. With the development of more ground-based GNSS networks and multifrequency/system GNSS satellite constellations, higher resolution and accurate parameters can, in the future, be retrieved from GNSS, including, coordinate, Earth orientation parameters, orbit, tropspheric and ionospheric products. With more and more spaceborne GPS reflectometry and refractometry missions in the near future (e.g., follow-on FORMOSAT-7/COSMIC-2 mission, CICERO and TechDemoSat-1), the refracted, reflected and scattered GNSS signals will remotely sense more detailed atmosphere, ocean, land, hydrology and cryosphere (Jin and Komjathy, 2010). Also the GNSS reflectometry together with ground observation networks of seismology and geodesy are expected to be applied into a geohazard warning system. Moreover, GNSS reflected signals may be used to monitor crustal deformation in the same way as Synthetic Aperture Radar (SAR) and in combination with other sensors, is expected to observe global-scale geodynamic processes.

\section{Summary}

In this paper, the main space geodetic techniques have been briefly introduced, including GNSS, VLBI, SLR, DORIS, InSAR, satellite gravimetry and altimetry. These techniques play key roles in monitoring and understanding the processes and interactions between the components of the Earth system with a high resolution and accuracy. Recent results of observing and understanding the Earth system variations are presented, e.g., atmospheric-ionospheric variations, sea level change, hydrologic cycle, glacier melting, crustal deformation and loadings, geocenter motion and $J_{2}$ variations, excitation of Earth rotation and atmospheric-solid Earth coupling etc. Furthermore, some questions and challenges on observing and understanding the Earth system variations have been discussed, as well as future developments in space geodesy.

\section{Acknowledgement}

This research is supported by the Main Direction Project of Chinese Academy of Sciences (Grant No. KJCX2-EW-T03), Shanghai Science and Technology Commission Project (Grant No. 12DZ2273300), Shanghai Pujiang Talent Program Project (Grant No. 11PJ1411500) and National Natural Science Foundation of China (NSFC) Project (Grant Nos. 11173050 and 11373059).

\section{References}

Abshire, J.B., Sun, X., Riris, H., Sirota, J.M., McGarry, J.F., Palm, S., Yi, D., Liiva, P., 2005. Geoscience laser altimeter system (GLAS) on the ICESat mission: on-orbit measurement performance. Geophys. Res. Lett. 32, L21S02, http://dx.doi.org/10.1029/2005GL024028.

Afraimovich, E., Ding, F., Kiryushkin, V., Astafyeva, E., Jin, S.G., Sankov, V., 2010. TEC response to the 2008 Wenchuan earthquake in comparison with other strong earthquakes. Int. J. Remote Sens. 31 (13), 3601-3613, http://dx.doi.org/10.1080/01431161003727747.

Altamimi, Z., Collilieux, X., Métivier, L., 2011. ITRF2008: an improved solution of the International Terrestrial Reference Frame. J. Geodesy 85 (8), 457-473, http://dx.doi.org/10.1007/s00190-011-0444-4.

Barnes, R., Hide, R., White, A., Wilson, C., 1983. Atmospheric angular momentum functions, length of day changes and polar motion. Proc. R. Soc. London, Ser. A 387, 31-73.

Barnett, T.P., 1984. The estimation of global sea level change: a problem of uniqueness. J. Geophys. Res. 89 (C5), 7980-7988.

Chen, Q., van Dam, T., Sneeuw, N., Collilieux, X., Weigelt, M., Rebischung, P., 2013. Singular spectrum analysis for modeling seasonal signals from GPS time series. J. Geodyn., http://dx.doi.org/10.1016/j.jog.2013.05.005 (this issue).

Cheng, M., Tapley, B.D., 2004. Variations in the Earth's oblateness during the past 28 years. J. Geophys. Res. 109, B09402, http://dx.doi.org/10.1029/2004JB003028.

Church, J.A., White, N.J., 2006. A 20th century acceleration in global sea-level rise. Geophys. Res. Lett. 33, L01602, http://dx.doi.org/10.1029/2005GL024826.

Dong, D., Fang, P., Bock, Y., Cheng, M.K., Miyazaki, S., 2002. Anatomy of apparent seasonal variations from GPS-derived site position time series 107 (B4), http://dx.doi.org/10.1029/2001JB000573, ETG 9 1-16.

Famiglietti, J., Lo, M., Ho, S.L., et al., 2011. Satellites measure recent rates of groundwater depletion in California's Central Valley. Geophys. Res. Lett. 38, L03403, http://dx.doi.org/10.1029/2010GL046442.

Feng, G., Jin, S.G., Zhang, T., 2013. Coastal sea level changes in the Europe from GPS, tide gauge, satellite altimetry and GRACE, 1993-2011. Adv. Space Res. 51 (6), 1019-1028, http://dx.doi.org/10.1016/j.asr.2012.09.011.

Gross, R.S., Fukumori, I., Menemenlis, D., 2003. Atmospheric and oceanic excitation of the Earth's wobbles during 1980-2000. J. Geophys. Res. 108 (B8), 2370, http://dx.doi.org/10.1029/2002JB002143.

Holgate, S.J., Woodworth, P.L., 2004. Evidence for enhanced coastal sea level rise during the 1990s. Geophys. Res. Lett. 31, L07305, http://dx.doi.org/10.1029/2004GL019626.

Hong, S.-H, Wdowinski, S., 2011. Evaluation of the quad-polarimetric RADARSAT2 observations for the wetland InSAR application. Can. J. Remote Sens. 37 (5), 484-492.

Hong, S.H., Wdowinski, S., Kim, S.W., 2010a. Evaluation of TerraSAR-X observations for wetland InSAR application. IEEE Trans. Geosci. Remote Sens. 48 (2), 864-873.

Hong, S.H., Wdowinski, S., Kim, S.W., Won, J.S., 2010b. Multi-temporal monitoring of wetland water levels in the Florida Everglades using interferometric synthetic aperture radar (InSAR). Remote Sens. Environ. 114 (11), 2436-2447.

Jacobson, M.D., 2010. Snow-covered lake ice in GPS multipath reception - theory and measurement. Adv. Space Res. 46 (2), 221-227, http://dx.doi.org/10.1016/j.asr.2009.10.013.

Jin, S.G., Zhu, W., 2002. Present-day spreading motion of the mid-Atlantic ridge. Chin. Sci. Bull. 47 (18), 1551-1555, http://dx.doi.org/10.1360/02tb9342.

Jin, S.G., Zhu, W.Y., 2003. Active motion of tectonic blocks in Eastern Asia: evidence from GPS measurements. Acta Geol. Sin. Engl. Ed. 77 (1), 59-63. http://dx.doi.org/10.1111/j.1755-6724.2003.tb00110.x.

Jin, S.G., Wang, J., Park, P., 2005. An improvement of GPS height estimates: stochastic modeling. Earth Planets Space 57 (4), 253-259. 
Jin, S.G., Park, J., Wang, J., Choi, B., Park, P., 2006. Electron density profiles derived from ground-based GPS observations. J. Navig. 59 (3), 395-401, http://dx.doi.org/10.1017/S0373463306003821.

Jin, S.G., Park, P., Zhu, W., 2007. Micro-plate tectonics and kinematics in Northeast Asia inferred from a dense set of GPS observations. Earth Planet. Sci. Lett. 257 (3-4), 486-496, http://dx.doi.org/10.1016/j.epsl.2007.03.011.

Jin, S.G., Park, J., 2007. GPS ionospheric tomography: a comparison with the IRI-2001 model over South Korea. Earth Planets Space 59 (4), 287-292.

Jin, S.G., Luo, O., Park, P., 2008. GPS observations of the ionospheric F2-layer behavior during the 20th November 2003 geomagnetic storm over South Korea. J. Geod. 82 (12), 883-892, http://dx.doi.org/10.1007/s00190-008-0217-x.

Jin, S.G., Luo, O., 2009. Variability and climatology of PWV from global 13year GPS observations. IEEE Trans. Geosci. Remote Sens. 47 (7), 1918-1924, http://dx.doi.org/10.1109/TGRS.2008.2010401.

Jin, S.G., Luo, O., Gleason, S., 2009. Characterization of diurnal cycles in ZTD from a decade of global GPS observations. J. Geod. 83 (6), 537-545, http://dx.doi.org/10.1007/s00190-008-0264-3.

Jin, S.G., Komjathy, A., 2010. GNSS reflectometry and remote sensing: new objectives and results. Adv. Space Res. 46 (2), 111-117, http://dx.doi.org/10.1016/j.asr.2010.01.014.

Jin, S.G., Chambers, D.P., Tapley, B.D., 2010a. Hydrological and oceanic effects on polar motion from GRACE and models. J. Geophys. Res. 115, B02403, http://dx.doi.org/10.1029/2009JB006635.

Jin, S.G., Zhu, W., Afraimovich, E., 2010b. Co-seismic ionospheric and deformation signals on the 2008 magnitude 8.0 Wenchuan Earthquake from GPS observations. Int. J. Remote Sens. 31 (13), 3535-3543, http://dx.doi.org/10.1080/01431161003727739.

Jin, S.G., Feng, G., Gleason, S., 2011a. Remote sensing using GNSS signals: current status and future directions. Adv. Space Res. 47 (10), 1645-1653, http://dx.doi.org/10.1016/j.asr.2011.01.036.

Jin, S.G., Zhang, L., Tapley, B.D., 2011b. The understanding of length-of-day variations from satellite gravity and laser ranging measurements. Geophys. J. Int. 184 (2), 651-660, http://dx.doi.org/10.1111/j.1365-246X.2010.04869.x.

Jin, S.G., Han, L., Cho, J., 2011c. Lower atmospheric anomalies following the 2008 Wenchuan Earthquake observed by GPS measurements. J. Atmos. Sol. Terr. Phys. 73 (7-8), 810-814, http://dx.doi.org/10.1016/j.jastp.2011.01.023.

Jin, S.G., Zhang, X.G., 2012. Variations and geophysical excitation of Earth's dynamic oblateness estimated from GPS, OBP, and GRACE. Chin. Sci. Bull. 57 (36), 3484-3492, http://dx.doi.org/10.1360/972011-1934.

Jin, S.G., Hassan, A., Feng, G., 2012. Assessment of terrestrial water contributions to polar motion from GRACE and hydrological models. J. Geodyn. 62, 40-48, http://dx.doi.org/10.1016/j.jog.2012.01.009.

Jin, S.G., Feng, G., 2013. Large-scale variations of global groundwater from satellite gravimetry and hydrological models, 2002-2012. Global Planet. Change, http://dx.doi.org/10.1016/j.gloplacha.2013.02.008.

Katzberg, S., Torres, O., Grant, M.S., Masters, D., 2006. Utilizing calibrated GPS reflected signals to estimate soil reflectivity and dielectric constant: results from SMEX02. Remote Sens. Environ. 100 (1), 17-28.

Katzberg, S.J., Dunion, J., 2009. Comparison of reflected GPS wind speed retrievals with dropsondes in tropical cyclones. Geophys. Res. Lett. 36, L17602, http://dx.doi.org/10.1029/2009GL039512.

Katzberg, S.J., Walker, R.A., Roles, J.H., Lynch, T., Black, P.G., 2001. First GPS signals reflected from the interior of a tropical storm: preliminary results from Hurricane Michael. Geophys. Res. Lett. 28 (10), 1981-1984, http://dx.doi.org/10.1029/2000GL012823.

Kim, S.-W., Wdowinski, S., Amelung, A., Dixon, T.H., Won, J.-S., 2013. Interferometric coherence analysis of the Everglades Wetlands, South Florida. IEEE Trans. Geosci. Remote Sens. 51, 1-15

Knudsen, P., Bingham, R., Andersen, O., Rio, M.H., 2011. A global mean dynamic topography and ocean circulation estimation using a preliminary GOCE gravity model. J. Geod. 85 (11), 861-879, http://dx.doi.org/10.1007/s00190-011-0485-8.

Komjathy, A., Maslanik, J.A., Zavorotny, V.U., Axelrad, P., Katzberg, S.J., 2000. Sea ice remote sensing using surface reflected GPS signals. In: Proceedings of the IEEE international Geosciences and Remote Sensing Symposium (IGARSS 2000), Honolulu, Hawaii, 24-28 July, pp. 2855-2857.

Larson, K.M., Small, E.E., Gutmann, E., Bilich, A., Braun, J., Zavorotny, V., 2008. Use of GPS receivers as a soil moisture network for water cycle studies. Geophys. Res. Lett. 35, L24405, http://dx.doi.org/10.1029/2008GL036013.
Martin-Neira, M., Caparrini, M., Font-Rosselo, J., et al., 2001. The PARIS concept: an experimental demonstration of sea surface altimetry using GPS reflected signals. IEEE Trans. Geosci. Remote Sens. 39, 142-150.

Massonnet, D., Feigl, K., 1998. Radar interferometry and its application to changes in the earth's surface. Rev. Geophys. 36 (4), 441-500, http://dx.doi.org/10.1029/97RG03139.

Pachauri, R.K., Reisinger, A. (Eds.), 2007. Climate Change 2007: Synthesis Report, Contribution of Working Groups I, II and III to the Fourth Assessment Report of the Intergovernmental Panel on Climate Change. IPCC, Geneva, Switzerland, p. 104.

Richards, J.A., Woodgate, P.W., Skidmore, A.K., 1987. An explanation of enhanced radar backscattering from flooded forests. Int. J. Remote Sens. 8, 1093-1100.

Rodell, M., Velicogna, I., Famiglietti, J., 2009. Satellite-based estimates of groundwater depletion in India. Nature 460, 999-1002, http://dx.doi.org/10.1038/ nature08238.

Schmidt, T., Wickert, J., Haser, A., 2010. Variability of the upper troposphere and lower stratosphere observed with GPS radio occultation bending angles and temperatures. Adv. Space Res. 46 (2), 150-161, http://dx.doi.org/10.1016/j.asr.2010.01.021.

Swenson, S., Wahr, J., 2006. Post-processing removal of correlated errors in GRACE data. Geophys. Res. Lett. 33, L08402, http://dx.doi.org/10.1029/2005GL025285.

Tapley, B., Bettadpur, S., Watkins, M., Reigber, C., 2004. The gravity recovery and climate experiment: mission overview and early results. Geophys. Res. Lett. 31, L09607, http://dx.doi.org/10.1029/2004GL019920.

Titov, O., 2010. VLBI2020: from reality to vision. In: Behrend, D., Baver, K.D. (Eds.) IVS 2010 General Meeting Proceedings. , pp. 60-64 (NASA/CP-2010-215864).

van Dam, T., Wahr, J.M., 1987. Displacements of the Earth's surface due to atmospheric loading: effects on gravity and baseline measurements. J. Geophys. Res. 92 (B2), 1281-1286

van Dam, T., Wahr, J., Milly, P.C.D., Shmakin, A.B., Blewitt, G., Lavallée, D., Larson, K.M., 2001. Crustal displacements due to continental water loading. Geophys. Res. Lett. 28 (4), 651-654

van Dam, T., Wahr, J., Lavalle'e, D., 2007. A comparison of annual vertical crustal displacements from GPS and gravity recovery and climate experiment (GRACE) over Europe. J. Geophys. Res. 112, B03404, http://dx.doi.org/10.1029/2006JB00433.

Wahr, J., Molenaar, M., Bryan, F., 1998. Time-variability of the Earth's gravity field: hydrological and oceanic effects and their possible detection using GRACE. J. Geophys. Res. 103 (32), 30205-30229.

Wdowinski, S., Amelung, F., Miralles-Wilhelm, F., Dixon, T.H., Carande, R., 2004. Space-based measurements of sheet-flow characteristics in the Everglades wetland, Florida. Geophys. Res. Lett. 31 (15.).

Wdowinski, S., Kim, S.W., Amelung, F., Dixon, T.H., Miralles-Wilhelm, F., Sonenshein, R., 2008. Space-based detection of wetlands' surface water level changes from L-band SAR interferometry. Remote Sens. Environ. 112 (3), 681-696.

Wdowinski, S., Hong, S.H., Mulcan, A., Brisco, B., 2013. Remote sensing observations of tide propagation through coastal wetlands. Oceanography 26 (3), 64-69, http://dx.doi.org/10.5670/oceanog.2013.46.

Wei, E., Yan, W., Jin, S.G., Liu, J., Cai, J., 2013. Improvement of Earth orientation parameters estimate with Chang'E-1 $\Delta$ VLBI Observations. J. Geodyn. http://dx.doi.org/10.1016/j.jog.2013.04.001.

Willis, P., Fagard, H., Ferrage, P., Lemoine, F.G., Noll, C.E., Noomen, R., Otten, M., Ries, J.C., Rothacher, M., Soudarin, L., Tavernier, G., Valette, J.-J., 2010 The International DORIS Service (IDS): toward maturity. Adv. Space Res. 45, http://dx.doi.org/10.1016/j.asr.2009.11.018.

Wolff, M., 1969. Direct measurement of the Earth's gravitational potential using a satellie pair. J. Geophys. Res. 74 (22), 5295-5300, http://dx.doi.org/10.1029/JB074i022p05295.

Wu, X., Heflin, M., Ivins, E., Fukumori, I., 2006. Seasonal and inter-annual global surface mass variations from multisatellite geodetic data. J. Geophys. Res. 111 B09401, http://dx.doi.org/10.1029/2005JB004100.

Zhang, L.J., Jin, S.G., Zhang, T.Y., 2012. Seasonal variations of Earth's surface loading deformation estimated from GPS and satellite gravimetry. J. Geod. Geodyn. 32 (2), 32-38.

Zhang, T.Y., Jin, S.G., 2013. Estimate of glacial isostatic adjustment uplift rate in the Tibetan Plateau from GRACE and GIA models. J. Geodyn. http://dx.doi.org/10.1016/j.jog.2013.05.002.

Zwally, H.J., Giovinetto, M.B., Li, J., Cornejo, H., Beckley, M.A., Brenner, A.C., Sabam, J.L., Yi, D., 2005. Mass changes of the greenland and antarctic ice sheets and shelves and contributions to sea-level rise: 1992-2002. J. Glaciol. 51, 509-527. 